\title{
Physico-chemical surface characterization of a bacterial population isolated from a milking machine
}

\author{
Pilar Teixeira $^{\mathrm{a}}$, Zulmira Lopes ${ }^{\mathrm{b}}$, Joana Azeredo ${ }^{\mathrm{a}}$, Rosário Oliveira ${ }^{\mathrm{a}}$, Maria João Vieira ${ }^{\mathrm{a}, *}$ \\ ${ }^{a}$ Centro de Engenharia Biológica, Universidade do Minho, Campus de Gualtar, 4710-057 Braga, Portugal \\ ${ }^{\mathrm{b}}$ Divisão de Leite e Lacticínios (DRAEDM), Avenida dos Templários APT 156, 4594-909 Paços de Ferreira, Portugal
}

Received 17 November 2003; accepted 5 March 2004

\begin{abstract}
The hydrophobicity of 26 species of bacteria representative of the main genera isolated from a rubber short milk tube, which is a constituent of a cluster from a milking machine, was determined. The materials forming the cluster namely rubber, stainless steel (SS) 316, stainless steel (SS) 304, glass and polymethylmethacrylate (PMMA) were also assayed in terms of hydrophobicity. In relation with the hydrophobicity of bacteria, all the strains of Lactobacillus lactis lactis as well as of Enterococcus faecalis are hydrophobic. Concerning Pseudomonas aeruginosa and Staphylococcus sciuri, some are hydrophobic and others are hydrophilic. All the materials are hydrophobic, being rubber, SS 316 and SS 304 the most hydrophobic surfaces while glass is the less hydrophobic.

The free energy of adhesion between the bacteria and the materials in aqueous medium was calculated and used to predict which material of the cluster has a higher ability for biofilm formation and by this way contribute for milk contamination due to the release of bacteria from the deposit. For all the situations studied, adhesion is thermodynamically favourable to SS 316 , SS 304 and rubber and less favourable to PMMA and glass.
\end{abstract}

(C) 2004 Elsevier Ltd. All rights reserved.

Keywords: Surface hydrophobicity; Bacterial adhesion; Microbial attachment; Milking machine; Dairy process

\section{Introduction}

Automatic milking systems are currently used in the dairy industry. In these systems, the cluster, which attaches to the udder, consists of four teatcup assemblies (each having a shell, a rubber liner and a short milk and short pulse tube), a claw, a long milk tube and long pulse tube. All these constituents are made of rubber, stainless steel or plastic, which are common materials in the food industry. As all inert surfaces, these materials are potential sites for biofilm formation, even when hygiene and sanitation programmes are correctly applied. Once established, the biofilm can act as a source of milk contamination due to the release of micro-organisms from the surface to the bulk fluid. It has been recognized that a greater understanding of the

\footnotetext{
*Corresponding author. Tel.: +351-253-604404; fax: +351-253678986.

E-mail address: mjv@deb.uminho.pt (M.J. Vieira).
}

interactions between the bacteria and the surfaces may play a significant role to control this problem.

The adhesion of bacteria to the surface is one of the prime steps in the biofilm formation process. This step is particularly affected by the physico-chemical characteristics of the micro-organisms and the materials surface involved. Several studies have demonstrated the importance of surface hydrophobicity in the adhesion process (van Loosdrecht et al., 1987; Husmark and Rönner, 1992; Millsap et al., 1996; Teixeira and Oliveira, 1999; Pereira et al., 2000). This property represents the wettability of a surface and, in aqueous medium, adhesion is favoured between hydrophobic surfaces, which can enter in closer contact by squeezing the water layer between them. According to Doyle (2000), bacteria and other microorganisms, including viral particles, have many different ways to use the hydrophobic effect in order to adhere to substrata. In fact, there are compelling reasons to believe that the hydrophobic effect may be the primary driving force for the adhesion of most pathogens (Duncan-Hewitt, 1990). 
Sinde and Carballo (2000) demonstrated the effect of hydrophobicity in the adhesion of Salmonella spp. and Listeria monocytogenes to stainless steel, rubber and polytetrafluor-ethylene, which are typical materials in the food industry. They found that Salmonellas strains are hydrophobic as well as Listeria monocytogenes and that bacteria attached in higher numbers to the more hydrophobic materials. Flint et al. (1997) examined the properties of the cell surface of 12 strains of streptococci, namely the hydrophobicity, and correlated those properties with the ability of the cell to attach to stainless steel surfaces. They observed that, in this case, there was no obvious relationship between hydrophobicity and attachment to stainless steel.

The purpose of the present work was to evaluate the potentiality of adhesion on some of the typical materials used in the milking machines by bacteria isolated at those environments.

\section{Materials and methods}

\subsection{Micro-organisms}

The micro-organisms used throughout this work were isolated from the cluster (rubber short milk tube-tube that connects the teatcup assemblies to the claw) of a milking machine in the north of Portugal, after the cleaning procedures. The internal surface was scraped with a sterile cotton-tipped swab and the recovered microbial cells were seeded on PCA agar plates and incubated during $24 \mathrm{~h}$ or $48 \mathrm{~h}$ at $30^{\circ} \mathrm{C}$. After that, colonies were picked randomly from the agar plates and the isolates were initially seeded on selective media, characterized according to Gram staining and oxidase and catalase activities. Phenotypic characterization of the isolates was carried out with API 20 NE strips (Biomerioux Vitek Inc., Hazelwood, Missouri) according to the manufacturer's instructions.

For contact angle determinations cells were incubated overnight at $30^{\circ} \mathrm{C}$ and were harvested by centrifugation (5 min at $5000 \mathrm{rpm})$, washed twice in phosphate buffer saline (PBS), twice in deionized water and resuspended in deionized water to a concentration of $1 \times 10^{\mathrm{a}}$ cell $/ \mathrm{ml}$.

\subsection{Materials}

The materials assayed were rubber of a short milk tube of the cluster, stainless steel (SS) $316 \quad 2 \mathrm{R}$ $(\mathrm{Ra}=1.15 \mu \mathrm{m})$, stainless steel (SS) $304 \quad 2 \mathrm{R}$ $(\mathrm{Ra}=1.17 \mu \mathrm{m}), \quad$ glass and polymethylmethacrylate (PMMA). All these materials are typically used in milking installations. The surface characterization of each type of material was performed by measuring contact angle on slides of $3.0 \times 2 \mathrm{~cm}$. Prior to the tests, the slides were carefully washed in detergent, ethanol and serial sterile water baths.

\subsection{Hydrophobicity and free energy of adhesion}

Hydrophobicity was evaluated through contact angle measurements and using the approach of van Oss and co-workers (van Oss et al., 1987, 1988, 1989). In this approach, the degree of hydrophobicity of a given material (1) is expressed as the free energy of interaction between two entities of that material when immersed in water (w) $\Delta G_{1 w 1}$. If the interaction between the two entities is stronger than the interaction of each entity with water $\Delta G_{1 \mathrm{w} 1}<0$ the material is considered hydrophobic. Conversely, if $\Delta G_{1 \mathrm{w} 1}>0$ the material is hydrophilic. $\Delta G_{1 \mathrm{w} 1}$ can be calculated through the surface tension components of the interacting entities, according to:

$$
\begin{aligned}
\Delta G_{1 \mathrm{w} 1}= & -2\left(\sqrt{\gamma_{1}^{\mathrm{LW}}}-\sqrt{\gamma_{\mathrm{w}}^{\mathrm{LW}}}\right)^{2} \\
& +4\left(\sqrt{\gamma_{1}^{+} \gamma_{\mathrm{w}}^{-}}+\sqrt{\gamma_{1}^{-} \gamma_{\mathrm{w}}^{+}}-\sqrt{\gamma_{1}^{+} \gamma_{1}^{-}}-\sqrt{\gamma_{\mathrm{w}}^{+} \gamma_{\mathrm{w}}^{-}}\right)
\end{aligned}
$$

where $\gamma^{\mathrm{LW}}$ accounts for the Lifshitz-van der Waals component of the surface free energy and $\gamma^{+}$and $\gamma$ are the electron acceptor and electron donor parameters, respectively, of the Lewis acid-base component $\left(\gamma^{\mathrm{AB}}\right)$, with $\gamma^{\mathrm{AB}}=2 \sqrt{\gamma^{+} \gamma^{-}}$.

The surface tension components of a solid material are obtained by measuring the contact angles of three pure liquids (one apolar and two polar), with wellknown surface tension components, followed by the simultaneous resolution of three equations of the form

$(1+\cos \theta) \gamma_{1}^{\mathrm{TOT}}=2\left(\sqrt{\gamma_{\mathrm{s}}^{\mathrm{LW}} \gamma_{1}^{\mathrm{LW}}}+\sqrt{\gamma_{\mathrm{s}}^{+} \gamma_{1}}+\sqrt{\gamma_{\mathrm{s}} \gamma_{1}^{+}}\right)$

where $\theta$ is the contact angle and $\gamma^{\mathrm{TOT}}=\gamma^{\mathrm{LW}}+\gamma^{\mathrm{AB}}$.

When studying the interaction between substances 1 and 2 that are immersed or dissolved in water (w), the total interaction energy, $\Delta G_{1 \mathrm{w} 2}^{\mathrm{TOT}}$, can be expressed as

$$
\begin{aligned}
\Delta G_{1 \mathrm{w} 2}^{\mathrm{TOT}}= & \gamma_{12}^{\mathrm{LW}}-\gamma_{1 \mathrm{w}}^{\mathrm{LW}}-\gamma_{2 \mathrm{w}}^{\mathrm{LW}}+2\left[\sqrt{\gamma_{\mathrm{w}}^{+}}\left(\sqrt{\gamma_{1}^{-}}+\sqrt{\gamma_{2}^{-}}-\sqrt{\gamma_{\mathrm{w}}^{-}}\right)\right. \\
& \left.+\sqrt{\gamma_{\mathrm{w}}^{-}}\left(\sqrt{\gamma_{1}^{+}}+\sqrt{\gamma_{2}^{+}}-\sqrt{\gamma_{\mathrm{w}}^{+}}\right)-\sqrt{\gamma_{1}^{+} \gamma_{2}^{-}}-\sqrt{\gamma_{1}^{-} \gamma_{2}^{+}}\right] .
\end{aligned}
$$

In this case, 1 represents the support material and 2 the bacteria. Thermodynamically, if $\Delta G_{1 \mathrm{w} 2}^{\mathrm{TOT}}<0$ adhesion is favourable. On the contrary, adhesion is not expected to occur if $\Delta G_{1 \mathrm{w} 2}^{\mathrm{TOT}}>0$.

\subsection{Contact angle measurement}

Contact angle measurements (at least 25 determinations for each liquid and for each material and micro- 
organisms) were performed automatically with the aid of an image analysis system (G2/G40) installed in a standard contact angle apparatus (Kruss-GmbH). The images were transmitted by a video camera to a 486 DX4 $100 \mathrm{MHz}$ personal computer for evaluation. All the measurements were performed at room temperature. In the case of bacterial cells the measurements were performed on bacterial layers deposited on membrane filters, according to a method described by Busscher et al. (1984). The probe liquids used were ultra-pure water, di-iodomethane and glycerol, both of analytical grade. Their surface tension components were taken from literature (Janczuk et al., 1993).

\section{Results and discussion}

The rubber short milking tube is one of the points more prone for biofilm formation in the milking machine. In the present case, even after the washing procedure under the strict standards followed by the dairy industry, it was possible to obtain a total of 37 isolates of bacteria from this tube. Among those bacteria, a total of 26 species representative of the main genera were selected for this study. These were 10 Pseudomonas aeruginosa (numbered as 1,4,6,7,10,14,63, $64,80,86$ ), three Lactobacillus lactis lactis (numbered as $8,62,73$ ), nine Staphylococcus sciuri (numbered as $45,50,54,55,56,60,78,79,82)$ and three Enterococcus faecalis (numbered as 70,76,77).

According to Vogler (1998), hydrophobic surfaces exhibit a water contact angle values higher than $65^{\circ}$, whereas hydrophilic ones exhibit water contact angle values lower than $65^{\circ}$. However, with this approach it is only possible to assess hydrophobicity qualitatively (Oliveira et al., 2001). Using the approach of van Oss (1997), it is possible to determine the absolute degree of hydrophobicity of any substance (1) vis-à-vis water (w), which can be precisely expressed in applicable S.I. units. Taking into account the values of the contact angles, it can be seen that only the strains of Enteroccous and Lactobacillus have similar values, principally for water. The other species studied cannot be classified as hydrophobic or hydrophilic. This fact is corroborated by the results presented by van der Mei et al. (1998), when studying 142 isolates of various species based on contact angle measurements. These authors verified that water and formamide contact angles vary widely and are the main discriminators between strains and species. On the other hand, apolar liquid contact angles vary less than water and formamide. The same happens with the results of the present work. Concerning the hydrophobicity of the bacterial population, a large variation can be observed between genera of bacteria and strains of the same species (Table 1). Pseudomonas aeruginosa 1 is slightly hydrophilic, the strains 6 and 86 are more
Table 1

Contact angle (in degrees) and free energy of interaction between the Micro-organisms isolated from the rubber short milk tube (1) immersed in water (w), $\Delta G_{1 \mathrm{wl} 1}$ and its components, in $\mathrm{mJ} / \mathrm{m}^{2}$

\begin{tabular}{lrrrrr}
\hline Micro-organism & \multicolumn{1}{l}{$\theta_{\mathrm{W}}$} & \multicolumn{1}{l}{$\theta_{\mathrm{F}}$} & \multicolumn{1}{l}{$\theta_{\mathrm{D}}$} & \multicolumn{1}{l}{$\Delta \mathrm{G}_{1 \mathrm{w} 1}$} \\
\hline Pseudomonas & 1 & $54.1 \pm 2.3$ & $49.0 \pm 2.3$ & $56.6 \pm 2.0$ & 6.1 \\
aeruginosa & 4 & $85.9 \pm 2.6$ & $56.1 \pm 1.9$ & $53.1 \pm 3.0$ & -60.7 \\
& 6 & $29.5 \pm 2.4$ & $38.2 \pm 1.9$ & $85.4 \pm 2.6$ & 19.6 \\
& 7 & $64.5 \pm 2.1$ & $54.9 \pm 1.5$ & $66.8 \pm 2.2$ & -9.1 \\
& 10 & $79.4 \pm 1.9$ & $56.4 \pm 2.1$ & $61.2 \pm 3.0$ & -41.5 \\
& 14 & $80.1 \pm 2.1$ & $71.4 \pm 2.9$ & $68.7 \pm 1.4$ & -27.9 \\
& 63 & $40.4 \pm 3.1$ & $75.8 \pm 2.8$ & $92.3 \pm 1.6$ & 84.7 \\
& 64 & $88.5 \pm 2.3$ & $62.9 \pm 1.9$ & $60.2 \pm 3.6$ & -59.1 \\
& 80 & $102.0 \pm 2.8$ & $101.3 \pm 1.8$ & $101.2 \pm 2.7$ & -48.6 \\
Lactobacillus lactis & 86 & $23.1 \pm 4.0$ & $29.4 \pm 1.6$ & $70.3 \pm 3.0$ & 26.0 \\
lactis & $66.0 \pm 0.6$ & $45.3 \pm 2.2$ & $60.4 \pm 1.3$ & -21.6 \\
Staphylococcus & 62 & $63.4 \pm 1.6$ & $49.9 \pm 1.3$ & $61.5 \pm 1.5$ & -12.9 \\
sciuri & 73 & $65.0 \pm 2.1$ & $46.6 \pm 2.3$ & $61.1 \pm 1.6$ & -18.7 \\
& 45 & $61.6 \pm 3.4$ & $46.8 \pm 1.7$ & $56.6 \pm 2.0$ & -13.3 \\
& 50 & $73.6 \pm 1.7$ & $54.3 \pm 1.8$ & $67.9 \pm 3.4$ & -27.5 \\
& 54 & $74.6 \pm 3.0$ & $52.4 \pm 3.4$ & $65.3 \pm 2.5$ & -31.3 \\
& 55 & $44.3 \pm 2.3$ & $39.1 \pm 2.6$ & $59.9 \pm 2.7$ & 12.5 \\
& 56 & $62.0 \pm 2.0$ & $50.4 \pm 2.2$ & $70.4 \pm 2.3$ & -8.1 \\
& 60 & $22.6 \pm 2.1$ & $18.8 \pm 1.2$ & $77.8 \pm 1.9$ & 13.9 \\
Eaterococcus & 78 & $66.3 \pm 2.8$ & $56.6 \pm 1.5$ & $80.9 \pm 1.0$ & -10.1 \\
& 79 & $81.5 \pm 4.0$ & $75.0 \pm 2.9$ & $68.1 \pm 3.2$ & -27.3 \\
& 82 & $64.8 \pm 2.9$ & $41.5 \pm 0.9$ & $79.6 \pm 3.1$ & -14.2 \\
& 70 & $63.1 \pm 1.5$ & $43.3 \pm 1.9$ & $49.2 \pm 2.8$ & -21.9 \\
& 76 & $71.7 \pm 3.0$ & $58.2 \pm 3.3$ & $58.8 \pm 1.6$ & -24.4 \\
& 77 & $62.6 \pm 1.2$ & $48.7 \pm 1.6$ & $60.1 \pm 2.8$ & -12.7 \\
\hline
\end{tabular}

$\theta_{\mathrm{W}}-$ Contact angle with water, $\theta_{\mathrm{F}}$ - Contact angle with formamide, $\theta_{\mathrm{D}}-$ Contact angle with di-iodomethane.

hydrophilic and the strain 63 is the most of all $\left(\Delta G_{1 \mathrm{w} 1}=84.7 \mathrm{~mJ} / \mathrm{m}^{2}\right)$. Conversely, the strains Pseudomonas 4, 7, 10, 14, 64 and 80 are hydrophobic, being the Pseudomonas aeruginosa 4 the most hydrophobic (with $\Delta G_{1 \mathrm{w} 1}=-60.7 \mathrm{~mJ} / \mathrm{m}^{2}$ ). All the strains of Lactobacillus lactis lactis and Enterococcus faecalis are hydrophobic. On the contrary, the strains of Staphylococcus sciuri are either slightly hydrophilic or slightly hydrophobic. These results are not surprising since, for example, Flint et al. (1997) when determining the hydrophobicity of 12 strains of streptococci observed that each individual thermophilic streptococci used had different degrees of hydrophobicity. These results emphasizes that generalizations concerning the hydrophobic properties of the bacterial cells shall not be made.

The values of $\Delta G_{1 \mathrm{w} 1}$ (Table 2) show that all the materials are hydrophobic, being SS 316, rubber and SS 304 the most hydrophobic surfaces. Considering the values of the contact angle of water, rubber was the most hydrophobic material $\left(\theta_{\mathrm{W}}>65^{\circ}\right)$ which is in accordance with several authors (Sinde and Carballo, 2000; Bruinsma et al., 2001). Flint et al. (2000) found a similar value for the contact angle of water in SS 304 $\left(85-86^{\circ}\right)$ and a smaller value to glass $\left(17-29^{\circ}\right)$. The values found in literature for PMMA -75 and 
Table 2

Contact angle (in degrees) and free energy of interaction between the materials (1) immersed in water (w), $\Delta G_{1 \mathrm{wl}}$ and its components, in $\mathrm{mJ} / \mathrm{m}^{2}$

\begin{tabular}{lllll}
\hline Material & $\theta_{\mathrm{W}}$ & $\theta_{\mathrm{F}}$ & $\theta_{\mathrm{D}}$ & $\Delta G_{1 \mathrm{wl}}$ \\
\hline Rubber & $96.4 \pm 3.0$ & $84.5 \pm 1.7$ & $53.7 \pm 2.1$ & -57.8 \\
SS 316 & $81.6 \pm 2.6$ & $54.3 \pm 2.0$ & $45.8 \pm 1.9$ & -58.1 \\
SS 304 & $83.2 \pm 3.5$ & $60.5 \pm 1.1$ & $52.3 \pm 3.2$ & -54.4 \\
Glass & $49.7 \pm 2.0$ & $22.0 \pm 2.2$ & $34.2 \pm 1.3$ & -14.8 \\
PMMA & $67.6 \pm 1.5$ & $57.7 \pm 2.8$ & $41.9 \pm 1.4$ & -18.9 \\
\hline
\end{tabular}

$\theta_{\mathrm{W}}$ - Contact angle with water, $\theta_{\mathrm{F}}-$ Contact angle with formamide, $\theta_{\mathrm{D}}-$ Contact angle with di-iodomethane.

$79^{\circ}$ - (Gottenbos et al., 2000; Bruinsma et al., 2001) are slightly higher than the value obtained in this work. Sinde and Carballo (2000) refer that SS 316 is more hydrophilic than SS 304, which is contrary to the results obtained in this work. Nevertheless, the hydrophobic character of stainless steel surfaces is very much dependent on their finishing.

It is well known that, in aqueous media, adhesion is favourable between hydrophobic surfaces, which can enter into close contact by squeezing the water layer between them. However, it should be stressed that adhesion between one hydrophobic and one hydrophilic surface or between two hydrophilic surfaces can occur (van Oss, 1997). Considering the hydrophobicity of the surfaces, the adhesion of Lactobacillus lactis lactis and all of strains of Enterococcus faecalis at SS 316, rubber and SS 304 is expected.

As previously mentioned, all the micro-organisms were isolated from the short milk tube (in rubber). However, there are other materials in the milking machine, being stainless steel 316, stainless steel 304, PMMA and glass the most commonly used.

In order to predict the ability of the micro-organisms to adhere to those surfaces and thus for biofilm formation, the free energy of interaction between the isolated micro-organisms and the materials, when immersed in water, was calculated (Table 3). For most of the cases, adhesion is thermodynamically favourable to all the materials studied since the total free energy of adhesion is negative $\left(\Delta G_{1 \mathrm{w} 2}^{\mathrm{TOT}}<0\right)$. Only for Pseudomonas aeruginosa 6, 63 and 86 and Staphylococcus sciuri 60, the adhesion process is not thermodynamically favourable to any of the materials studied $\left(\Delta G_{1 \mathrm{w} 2}^{\mathrm{TOT}}>0\right)$. The total free energy of adhesion between the bacteria and the materials, when immersed in water, is very similar for SS 316 and for SS 304 as well as for rubber where adhesion is more prone to occur, since the total free energy of adhesion is negative. However, adhesion is less favourable to glass and to PMMA, being glass the material which is expected to promote less adhesion (values of $\Delta G_{1 \mathrm{w} 2}^{\mathrm{TOT}}$ less negative). It should be expected in a less extent to PMMA and to glass. It must be noted that
Table 3

Free energy of adhesion between the microorganisms isolated from the rubber short milk tube (1), and the support material (2), when immersed in water (w), $\Delta G_{1 \mathrm{w} 2}^{\mathrm{TOT}}$, in $\mathrm{mJ} / \mathrm{m}^{2}$

\begin{tabular}{|c|c|c|c|c|c|c|}
\hline \multicolumn{2}{|l|}{ Micro-organism } & \multicolumn{5}{|l|}{$\Delta G_{1 \mathrm{w} 2}^{\mathrm{TOT}}$} \\
\hline & & Rubber & SS 316 & SS 304 & Glass & PMMA \\
\hline Pseudomonas & 1 & -20.5 & -25.9 & -23.1 & -4.4 & -4.0 \\
\hline \multirow{9}{*}{ aeruginosa } & 4 & -61.8 & -59.8 & -58.2 & -36.3 & -47.2 \\
\hline & 6 & 10.8 & 5.4 & 6.7 & 16.8 & 21.4 \\
\hline & 7 & -27.5 & -30.3 & -28.4 & -9.5 & -12.2 \\
\hline & 10 & -49.5 & -48.8 & -47.2 & -26.8 & -35.0 \\
\hline & 14 & -41.2 & -43.2 & -41.1 & -16.8 & -22.2 \\
\hline & 63 & 19.2 & 8.0 & 10.9 & 31.9 & 41.3 \\
\hline & 64 & -60.3 & -58.4 & -56.9 & -33.9 & -44.7 \\
\hline & 80 & -45.1 & -44.7 & -43.9 & -14.6 & -23.1 \\
\hline & 86 & 6.4 & -0.2 & 1.9 & 13.1 & 18.2 \\
\hline Lactobacillus lactis & 8 & -35.4 & -36.4 & -34.7 & -17.6 & -22.4 \\
\hline \multirow[t]{2}{*}{ lactis } & 62 & -30.0 & -32.6 & -30.5 & -12.3 & -15.3 \\
\hline & 73 & -33.4 & -34.9 & -33.1 & -15.7 & -20.0 \\
\hline Staphylococcus & 45 & -30.5 & -33.5 & -31.2 & -13.0 & -15.8 \\
\hline \multirow[t]{8}{*}{ sciuri } & 50 & -39.6 & -39.5 & -38.2 & -19.7 & -26.1 \\
\hline & 54 & -42.8 & -42.2 & -40.9 & -22.5 & -29.6 \\
\hline & 55 & -11.9 & -17.4 & -14.9 & 0.5 & 2.2 \\
\hline & 56 & -24.6 & -26.7 & -25.1 & -8.4 & -11.1 \\
\hline & 60 & 7.6 & 3.0 & 4.2 & 12.3 & 16.2 \\
\hline & 78 & -23.5 & -24.7 & -23.7 & -7.1 & -10.5 \\
\hline & 79 & -42.0 & -44.7 & -42.4 & -16.3 & -21.5 \\
\hline & 82 & -27.6 & -26.2 & -25.9 & -13.4 & -19.1 \\
\hline Enterococcus & 70 & -36.1 & -38.6 & -36.2 & -17.7 & -21.6 \\
\hline \multirow[t]{2}{*}{ faecalis } & 76 & -38.8 & -41.1 & -38.9 & -17.4 & -22.0 \\
\hline & 77 & -29.9 & -32.6 & -30.5 & -12.3 & -15.3 \\
\hline
\end{tabular}

albeit, in some cases, adhesion to rubber is not expected, adhesion did occur. This means that other factors may be involved in the adhesion process: micro-organisms can produce exopolymers and specific cellular structures (adhesins) that can contribute to the adhesins event.

\section{Acknowledgements}

The authors acknowledge Ana Pacheco and Joana Peralta for the valuable help during the experimental work and the Financial support of INIAP (Ministerio da Agricultura, do Desenvolvimento Rural e das Pescas) through Project AGRO 205.

\section{References}

Bruinsma, G.M., Abbing, M.R., van der Mei, H.C., Busscher, H.J., 2001. Effects of cell surface damage on surface properties and adhesion of Pseudomonas aeruginosa. J. Microbiol. Meth. 45, 95-101.

Busscher, H.J., Weerkamp, A.H., van der Mei, H.C., van Pelt, A.W.J., de Jong, H.P., Arends, J., 1984. Measurements of the surface free energy of bacterial cell surfaces and its relevance for adhesion. Appl. Environ. Microbiol. 48, 980-983. 
Doyle, R.J., 2000. Contribution of the hydrophobic effect to microbial infection. Microbes Infect. 2, 391-400.

Duncan-Hewitt, W.C., 1990. Nature of the hydrophobic effect. In: Doyle, R.J., Rosenberg, M. (Eds.), Microbial Cell surface Hydrophobicity. ASM Publications, Washington DC, pp. 39-73.

Flint, S.H., Brooks, J.D., Bremer, P.J., 1997. The influence of cell surface properties of thermophilic streptococci on attachment to stainless steel. J Appl. Microbiol. 83, 508-517.

Flint, S.H., Brooks, J.D., Bremer, P.J., 2000. Properties of the stainless steel substrate influencing the adhesion of thermo-resistant streptococci. J. Food Eng. 43, 235-242.

Gottenbos, B., van der Mei, H.C., Busscher, H.J., 2000. Initial adhesion and surface growth of Staphylococcus epidermidis and Pseudomonas aeruginosa on biomedical polymers. J. Biomed. Mater. Res. 50, 208-214.

Husmark, U., Rönner, U., 1992. The influence oh hydrophobic electrostatic and morphologic properties on the adhesion of Bacillus spores. Biofouling 5, 335-344.

Janczuk, B., Chibowski, E., Bruque, J.M, Kerkeb, M.L., GonzalezCaballero, F.J., 1993. On the consistency of surface free energy components as calculated from contact angle of different liquids: an application to the cholesterol surface. J. Colloid Interface Sci. $159,421-428$.

Millsap, K.W., Reid, G., van der Mei, H.C., Busscher, H.J., 1996. Adhesion of Lactobacillus species in urine and phosphate buffer to silicone rubber and glass under flow. Biomaterials 18, 87-91.

Oliveira, R., Azeredo, J., Teixeira, P., Fonseca, A.P., 2001. The role of hydrophobicity in bacterial adhesion. In: Gilbert, P., Allison, D., Brading, M., Verran, J., Walker, J. (Eds.), Biofilm Community Interactions: Chance or Necessity? Bioline, Cardiff, pp. 11-22.
Pereira, M.A., Alves, M.M., Azeredo, J., Mota, M., Oliveira, R., 2000. Influence of physico-chemical properties of porous microcarriers on the adhesion of an anaerobic consortium. J. Ind. Microbiol. Biotechnol. 24, 181-186.

Sinde, E., Carballo, J., 2000. Attachment of Salmonella spp. and Listeria monocytogenes to stainless steel, rubber and polytetrafluorethylene: the influence of free energy and the effect of commercial sanitizers. Food Microbiol 17, 439-447.

Teixeira, P., Oliveira, R., 1999. Influence of surface characteristics on the adhesion of Alcaligenes denitrificans to polymeric substrates. J. Adhesion Sci. Technol. 13, 1287-1294.

van der Mei, H.C., Bos, R., Busscher, H.J., 1998. A reference guide to microbial cell surface hydrophobicity based on contact angles. Colloid Surf. B: Biointerfaces 11, 213-221.

van Loosdrecht, M.C.M., Lyklema, J., Norde, W., Schraa, G., Zehnder, A.J.B., 1987. The role of bacterial cell wall hidrophobicity in adhesion. Appl. Environ. Microbiol. 53, 1893-1897.

van Oss, C.J., 1997. Hidrophobicity and hydrophilicity of biosurfaces. Curr. Opin. Colloid. Interfac. Sci. 2, 503-512.

van Oss, C.J., Chaudhury, M.K., Good, R.J., 1987. Monopolar surfaces. Adv. Colloid Interface Sci. 28, 35-64.

van Oss, C.J., Ju, L., Chaudhury, M.K., Good, R.J., 1989. Estimation of the polar parameters of the surface tension of liquids by contact angle measurements on gels. J. Colloid Interface Sci. 128, 313-319.

van Oss, C.J., Chaudhury, M.K., Good, C.J., 1988. Additive and nonadditive surface tension components and the interpretation of contact angles. Langmuir 4, 884-891.

Vogler, E.A., 1998. Structure and reactivity of water at biomaterial surfaces. Adv. Colloid. Interface. Sci. 74, 69-117. 